\title{
Ecological and Evolutionary Principles for Secondary Education: Analyzing Career and Tech Ed
}

\author{
George B. Richardson ${ }^{1,4}$ - Marisa E. Castellano ${ }^{2}$ - James R. Stone ${ }^{3} \cdot$ Blair K. Sanning ${ }^{1}$
}

Published online: 21 October 2015

(C) Springer International Publishing 2015

\begin{abstract}
Current approaches to secondary education expose students to cultural information and environmental conditions that were not typical features of youth development for the vast majority of human evolution. Understanding the mismatch between adolescents' evolved information processing biases and the educational content and environmental cues they often experience in school can help us to identify and/ or develop educational approaches that will work with student biases in attention and motivation, rather than against them. In this paper, we present an evolutionary perspective on adolescent learning, review life history theory, and describe how adolescents adopting a fast life history strategy (fast LHS) are especially susceptible to the mismatch between evolved biases and modern schooling. We then argue that learning in context is an approach that is more consistent with adolescents' evolved biases than traditional academic school environments and suggest that career and technical education (CTE) is an existing model that can be used successfully in secondary education, especially with students following a fast LHS. We conclude with future directions for CTE research and also applications of evolutionary theory to education and educational psychology.
\end{abstract}

George B. Richardson

george.richardson@uc.edu

University of Cincinnati, Cincinnati, OH, USA

2 University of Illinois, Urbana-Champaign, Champaign, IL, USA

3 National Research Center for Career and Technical Education at Southern Regional Education Board, Atlanta, GA, USA

4 Substance Abuse Counseling Program, School of Human Services, College of Education, Criminal Justice, and Human Services, University of Cincinnati, 6305B RECCENTER, Cincinnati, OH, USA
Keywords Evolutionary educational psychology $\cdot$ Life history theory $\cdot$ At-risk adolescents $\cdot$ Secondary education . Career and technical education

Current approaches to secondary education expose students to cultural information and environmental conditions that were not typical features of youth development for the vast majority of human evolution (Geary 2011). This implies a potential for mismatch between adolescents' evolved information processing biases and the educational content and environmental cues they often experience in school. Understanding evolved information processing biases that are relevant to secondary education, along with the survival and reproductive challenges these biases helped our ancestors solve, can help us to identify and/or develop educational approaches that will work with student biases in attention and motivation, rather than against them. In this paper, we review (1) the survival and reproductive challenges faced by adolescents, (2) several information processing biases that evolved to solve these challenges, (3) mismatches between features of modern school environments and student information processing biases that may contribute to poor achievement, discipline occurrences, and dropout, and (4) how some students are particularly maladapted to modern school contexts because of their home and neighborhood contexts. We go on to outline some guiding theoretical principles for an evolutionarily informed secondary education and discuss career and technical education (CTE) as a largely evolutionarily consistent approach.

\section{Survival and Reproductive Challenges Faced by Adolescents}

Adolescents are more likely to engage in high-risk behaviors than people in any other stage of development (Ellis et al. 
2012). High-risk behaviors such as substance abuse, multipartner sex, and delinquency are prohibited in school settings and have been linked to poorer academic achievement (Hallfors et al. 2002; University of Minnesota 2007). In the developmental literature, high-risk behaviors have been conceptualized as pathological and many intervention approaches to reducing their prevalence have been developed and studied (e.g., substance abuse prevention, sex education, and notolerance approaches to bullying; Ellis et al. 2012; Hansen et al. 2007; Nation et al. 2003; Roe and Becker 2005; Sobeck et al. 2006; Wandersman and Florin 2003). By and large, these approaches can be framed as working against adolescents' motivations to engage in high-risk behaviors because they attempt to modify these motivations directly or eliminate their behavioral manifestations.

From evolutionary and economic perspectives, risk is conceptualized as variance around a mean payoff (Figueredo and Jacobs 2010). Riskier behaviors are characterized by greater variance in potential payoffs, but not necessarily a less favorable average outcome. Many highrisk behaviors may produce net gains despite their potential for causing serious harm. As noted by Ellis et al. (2012), developmental approaches have generally focused on the harm that can result from high-risk behavior, leaving aside the potential gains. This focus has made it difficult to describe why adolescents are motivated to engage in high-risk behaviors, which is important because this information could be used to craft approaches to improving education that work with adolescents' motivations, rather than against them. Specifically, this information could be used to frame educational goals as pathways to overcoming problems adolescents are already motivated to solve, create educational processes that work with the information processing biases that have evolved to solve these recurrent problems, and identify existing approaches that are consistent with these principles.

Adolescence marks the transition from pre-reproductive to reproductive status, or the period when people begin to develop into reproductively competent individuals. Given this context, perhaps it should be unsurprising that sexual promiscuity and competition peak during adolescence as young people begin competing to control resources, negotiate status, and attract mates (Ellis et al. 2012; Weisfeld 1999; Weisfeld and Coleman 2005). To meet these challenges, adolescents undergo a punctuated change in a number of physiological, psychological, and social domains. For instance, adolescents begin to develop secondary sexual characteristics, stay up later at night (when most sexual activity takes place), eat more, increase their romantic involvement, exhibit greater sensation seeking and aggression, and begin pulling away from parents and/or caregivers (for a review, see Ellis et al. 2012). In the context of these changes, adolescents are keenly sensitive to socioenvironmental input and experience rapid learning and behavioral changes that often persist into adulthood (Ellis et al. 2012).

Education-Relevant Changes in Adolescent Brain Organization and Cognition. As young people enter adolescence, they are faced with a new set of survival and reproductive challenges. High-risk behaviors are often used in efforts to overcome these new challenges, although they may violate school norms and rules and can detract from academic achievement and attainment. Adolescence is also marked by dramatic changes in the frontal cortex (FC) that underpin or co-occur with the broad developmental changes discussed above (Giedd et al. 1999). Some researchers have estimated that the adolescent brain may lose as many as 30,000 synapses per second (e.g., Rakic et al. 1994), accounting for part of the gross loss in FC volume during this period. The FC is also the last area of the brain to complete myelination, and this does not occur until well into young adulthood (Spear 2002). This is important because the FC plays a central role in the decision making, emotional regulation, behavioral inhibition, and delay of gratification essential to investment in personal or embodied capital (e.g., academic success; for a review, see Figueredo et al. 2006).

According to Goldman et al. (2006), cognitive processing translates individuals' experiences into expectancies, which prepare them for future encounters with similar circumstances. Expectancies contain the value of rewards, along with the probability of achieving them through particular behavioral strategies (Goldman et al. 2006; Higgins and Spiegal 2004; Redish et al. 2008; Eccles and Wigfield 2002). The FC is responsible for the hierarchical integration of contextually related expectancies into networks or cognitive schemas, which associate salience (i.e., wanting) with long-term goals and current behavioral alternatives (Carbon and Albrecht 2012; Conrey and Smith 2007; Goldman et al. 2006; Lende and Smith 2002; Ross and Hill 2002; Stacy and Wiers 2006). When the most salient goals in the hierarchy must be realized in the future, self-control is deployed to regulate behavior in service of these superordinate goals (Duckworth and Gross 2014).

Stemming from the above, one reason adolescents engage in immediately gratifying socially deviant or delinquent behaviors (i.e., high-risk behaviors), and simultaneously experience difficulty investing in academics, is that they are not yet able to fully associate salience with long-term payoffs and the behaviors needed to produce them. This means they may experience difficulty forming positive educational utility beliefs (i.e., that education is useful or valuable; see Eccles and Wigfield 2002). In addition, they are not yet fully able to exert self-control to inhibit pre-potent responses (i.e., impulses) that may conflict with achievement of more valuable future outcomes (e.g., educational attainment). This immature nature of the frontal cortex during adolescence poses a challenge for 
educators, who often attempt to engage secondary students in learning that will pay off long-term and in unfamiliar contexts.

\section{Education-Relevant Information Processing Biases}

As people navigate adolescence, they are assisted by cognitive processing biases that prepare them for reliable and efficient detection, attention, and learning related to survival and reproductively valuable information. These biases evolved in response to recurrent problems faced by ancestral humans (Geary and Flinn 2001; Haselton et al. 2009; Haselton et al. 2005). Some of these biases, such as implicit fear of snakes, are infrequently relevant to school contexts, while others, such as bias for attending to faces and inferring from them the emotions of others, can be critical for guiding social behavior in schools (Damasio 2003; Haselton et al. 2005). For instance, implicit dominance and submission motives help coordinate social interactions among individuals by automatically activating submission in response to larger or higher-status individuals who would be too costly to challenge, or by automatically activating dominance when this response is likely adaptive (van Honk and Schutter 2007). In addition, people have attentional and processing biases for out-group and ingroup individuals that facilitate quick classification of conspecifics as either friends or foes and, on this basis, prepare friendly or unfriendly behavioral responses (Haselton et al. 2005, 2009). Geary (2011) calls our general predisposition for learning information that helps us control our social worlds, bias for folk psychology (p. 8).

Adolescents' concern with social context also extends to competition for control of their physical worlds. According to Geary (2011), folk biological and physics modules enable people to classify the natural world of plants and animals, construct representations of three-dimensional spaces, and carry out guided movement. Humans intuitively learn rudimentary hunting, foraging, and weaponry skills. They also have biases for learning and conceptualizing numbers and time (Gallistel and Gelman 1992). Among secondary students, all these implicit learning biases manifest as complex affinities for knowledge of strategies, skills, and competitive outcomes related to activities such as sports, along with knowledge of the characteristics, behaviors, and uses of animals and plants (e.g., 4-H club). Many school children express more interest in sports-related achievement than core academic areas (Eccles et al. 1993; Geary et al. 2003). From an evolutionary perspective, this is unsurprising.

In addition to biases for specific types of content, young people have biases for learning via modalities that correlated with reproductive success in ancestral environments. In traditional societies, learning often occurs via exploration and play, ${ }^{1}$ storytelling that transmitted moral and other cultural information across generations (Jordan 1989), and apprenticeship-like pedagogy that included scaffolding by more skilled individuals and experiential or active learning (i.e., learning by doing; Brown 1991; Collins et al. 1989; Geary 2011; Lancy 2010, 2012). In the context of storytelling and apprenticeship-like pedagogy, status-bearing adults enabled youth to learn the competencies prerequisite to adult roles.

\section{Mismatch Between Ancestral Environments and Modern Schools}

In modern schools, core academic areas such as math and science are taught in classrooms that are largely disconnected from students' local ecologies. Secondary teachers are rarely also professionals working out in the community. Most often, secondary teaching is a full-time job. This implies that students may not be able to conceptualize many of the ways that studying biology now might translate into resource control or status in the distant future. Further, some secondary students never take a psychology course, so they may not learn how basic science can be brought to bear on their understanding of the "really important things," like their conflicts with boyfriends and girlfriends, or their perceived status. Today, the experiences that correlated with becoming a competent adult in traditional societies have been largely replaced with teacher-directed explicit classroom instruction (Geary 2011). We do not mean to cast an unfavorable light on this development. Most children need explicit classroom instruction to learn to read and write (Hindson et al. 2005). However, greater recognition of the mismatch between modern and ancestral human environments could enable educators to identify or develop educational approaches that engage students using processes and contexts that work with their evolved preference for exploration, storytelling, and apprenticeship, and also relate core knowledge to folk domains and adolescents' motives for resource control, status, and mates.

We recognize that some educators may prefer not to frame education as a pathway to resource control, status, and mates. Instead, they may favor the view that education is a means to a higher purpose such as the common good. But, these ends are not mutually exclusive, and we need not look far for cultural evidence of how appealing to adolescents' motives for power and mates works. Just consider the massive popularity of hiphop and R\&B songs that have appealed to these desires through their lyrics. To make core content interesting to adolescents, especially at-risk adolescents (see discussion below),

\footnotetext{
${ }^{1}$ We note that biases for learning through play and exploration are not by any means limited to adolescence and are observed cross-culturally in the context of childhood as well (Lancy 2010).
} 
we need to show how it is useful in their particular biopsychosocial context. In other words, we need to show adolescents that prosocial behavior and investment in embodied capital are useful pathways to the same functional outcomes they expect to achieve through high-risk behavior. To achieve this, educators could intervene to help adolescents form positive educational utility beliefs by focusing more on outcomes that can be framed as improved resource control, status, and access to mates.

\section{An Evolutionary Perspective on At-Risk Students}

According to Geary (2011), the evolved cognitive adaptations that allowed ancestral humans "to anticipate changing conditions and to generate and mentally rehearse potential behavioural responses" (p. 2) now allow modern humans to learn novel cultural information such as algebra and written language. These adaptations include intelligence and also selfcontrol or executive functions (i.e., attention shifting, inhibition, and working memory; Ardila 2008; Barkley 2001), which are well-known correlates of academic success (e.g., Alloway and Alloway 2010; Aronen et al. 2004; Laidra et al. 2007). Recent research suggests that executive functioning is biologically sensitive to context (Del Giudice et al. 2011; Ellis et al. 2009). For instance, low socioeconomic status and maternal stress appear to contribute to the development of executive dysfunction among children and adolescents (Del Giudice et al. 2011).

Life History Theory and Education. Life history theory provides a biological explanation of the link between environmental conditions and cognitive functioning (Chisholm 1999; Figueredo et al. 2006). According to life history theory, species fall along a fast-to-slow reproductive continuum. At the fast end, organisms such as fish inhabit uncertain and high predation environments, reproduce early, and invest in offspring quantity rather than quality; at the slow end, elephants experience greater safety and predictability, delay reproduction, and invest in offspring quality at the expense of quantity (e.g., through parenting; Geary and Flinn 2001). The evolutionary logic is that when conditions are safe and predictable, investments in domains such as somatic effort (e.g., health) and parenting are more likely to pay off given that mortality is lower and the future can be predicted, while investment in early reproduction and mating effort are more likely to pay off given environmental harshness and unpredictability (Figueredo et al. 2006; Kaplan and Gangestad 2005).

The fast-to-slow life history spectrum has been documented among humans at various times and in various places (for a reviews, see Ellis et al. 2009; Figueredo et al. 2006; Del Giudice 2014). Among modern humans in Western societies, fast life history strategy (fast LHS) appears to be characterized by higher levels of mating effort, risk taking, earlier timing of puberty and childbirth, and antisocial or socially antagonistic behavior, while slow life history strategy (slow LHS) seems to be characterized by delayed reproduction, greater mental and physical health, higher levels of parenting effort, and prosocial or cooperative behavior (Del Giudice 2014; Ellis et al. 2009). Relevant to education, slow LHS is also characterized by greater investment in personal or embodied capital (Figueredo et al. 2006). Consistent with the predictions of life history theory, slower LHS seems to reflect predictability and safety, while faster LHS reflects unpredictability and harshness (Ellis et al. 2009; Kaplan and Gangestad 2005; Ross and Hill 2002).

Life history research suggests that those who have inhabited dangerous and unpredictable environments are more likely to have sensational interests (Weiss et al. 2004), take greater risks and engage in impulsive behaviors (Ellis et al. 2012), abuse psychoactive substances (Richardson et al. 2014), have more sexual partners (Richardson et al. 2014; Figueredo et al. 2006), and report more delinquent behaviors (Del Giudice et al. 2011). These findings suggest that some students are less likely to behave in accordance with school rules and more likely to accrue discipline occurrences due to their engagement in fast LHS.

There is also accumulating evidence that cognition mediates the expression of LHS. Richardson and Hardesty (2012) reviewed evidence consistent with a link between fast life history strategy and reliance on implicit cognitive processing, while Figueredo et al. (2006) provided an extensive review of evidence that brain development mediates the development and expression of faster or slower LHS. For instance, individual differences in executive functioning and the development of brain structures such as the prefrontal cortex have been documented and tied to LHS and environmental conditions (Del Giudice et al. 2011; Figueredo et al. 2006; Ellis et al. 2009). Taken together, the literature seems to imply that more implicit or automatic cognition enables humans to survive and reproduce quickly given unfavorable conditions, while more deliberate cognition (i.e., "effortful" control) enables humans to map out predictable environments and coordinate behavior within groups to achieve longer-term goals (see also Gilbert 1998).

Importantly, research suggests that executive functions integrate information about the value of outcomes (Pessoa 2009; Taylor et al. 2004). This may imply that executive dysfunction prevents students from forming positive educational utility beliefs (i.e., favorable expectancies about formal education; Eccles and Wigfield 2002). Both educational utility beliefs (Conley 2012; Eccles and Wigfield 2002; Harackiewicz et al. 2012) and executive functioning (Alloway and Alloway 2010; Aronen et al. 2004; Laidra et al. 2007; for measurement as self-control, see Duckworth and Carlson 2013; Mischel 2014) have been theoretically and empirically tied to academic outcomes such as achievement and attainment. Thus, it seems plausible that students employing a faster LHS are less 
likely to achieve well in school because of executive dysfunction that inhibits the formation of the positive educational utility beliefs, along with the self-control necessary for educational achievement/attainment. It is important to note that from an evolutionary perspective, executive dysfunction is not necessarily viewed as pathological but can often be seen as an adaptation to conditions requiring diffuse attentional style and quick behavioral activation. Our human ancestors often inhabited conditions in which these characteristics would have been quite useful given that the environment contained imminent threats and scarce resources that required immediate behavioral responses. Consistent with this conceptualization, children with executive dysfunction (i.e., ADHD) display superior associative learning under stressful conditions (Gatzke-Kopp 2011). This finding extends to other species. For instance, rats exposed to insensitive caregiving manifest stymied cognitive development (e.g., shorter dendritic branch lengths) but better learning and memory under stressful conditions (Del Giudice et al. 2011).

Sex Differences. Research has documented sex differences in life history strategy such that males tend to fall closer to the fast end of the life history spectrum than females (Del Giudice 2009). These differences are thought to reflect a basic reality of male and female biology_females must expend far more parental investment to reproduce successfully, implying that a quantity over quality strategy is less viable and indiscriminate mating is much more costly for females, compared with males (Trivers 1972). Indeed, evolutionarily informed studies have shown that human females tend to be the choosier or more selective sex (Schmitt et al. 2001), while males tend to engage in greater intra-sexual competition to gain favor or access to females (Gangestad and Simpson 2000). These sex differences are reflected in greater average muscle tone and strength among males, which aides in physical competitions, fights, intergroup warfare (Van Vugt et al. 2007), and hunting (Wood and Eagly 2002), and also in the larger average waist-to-hip ratios (WHRs) among females, which signal fertility (Ellis et al. 2012). Indeed, males perceive that larger WHRs are more attractive, while females tend to prize greater strength and athleticism among males (Ellis et al. 2012). Illustrating these differences further, males devote more effort to status striving (Buss 2008) and display more high-risk behavior for potential reproductive gains within a hierarchy (Nettle 2009). Furthermore, males exhibit higher levels on present orientation (Kruger et al. 2008) and also sensation seeking and motivational impulsivity (Cross et al. 2011). However, some of these differences may be sensitive to context, as Wilson and Daly (2004) found that males discount the future more than females, but especially when primed with physically attractive females. In contrast to males, females tend to expend more parenting effort and exhibit risk aversion (e.g., greater sensitivity to retribution or punishment and other threats; Campbell 2002; Cross et al. 2011).

Of course, the average differences discussed above should not be taken as negating the substantial behavioral variation found within each sex (Rhen and Crews 2002) or the role of culture/socialization (e.g., in explaining variation in societal roles taken on by males and females; Mealey 1999; Wood and Eagly 2002). There is also a lot of variation in the sorts of females to whom males are attracted, and vice versa, and it is important to note that in some cases, sex differences are universal but only small in magnitude (Mealey 1999). Finally, documented variations in human traits that stem from biological factors do so within an environment. To illustrate, genetic factors account for much of the variance in psychoactive substance use (Urbanoski and Kelly 2012). However, if substances were no longer available, genes would then account for zero variance in substance use. The role of genetic factors can often be understood in this way-as interacting with environments that constrain or allow their expression. Stemming from this, sex differences can be understood as reflecting biology in environments as they currently exist. In the distant future, such differences could be more or less attributable to biology and more or less evident.

\section{Implications for Modern Secondary Education}

Modern secondary educational environments require long periods of sitting, devotion of attention, and working memory to stimuli that are not very relevant to short-term survival, along with inhibition of fast LHS behavioral responses to survival and reproductively relevant cues that are often present in schools. For instance, students experience cues to the availability of mates, challenges posed by intra-sexual competitors, and behavioral constraints imposed by older and higher-status group members. Fast LHS responses to these cues could be expected to include displays of risk taking and dominance or reproductive viability to win access to mates, fight-or-flight responses to intra-sexual challengers, and defiance of higher status group members.

This life history perspective sheds light on the nature of students who are at risk for poor academic achievement, discipline occurrences, and dropout. From this perspective, many students will experience these outcomes because they have inhabited harsh and unpredictable home and/or neighborhood environments and developed fast life history strategies, which are adaptive but also problematic in modern school contexts. This is because their experiences and executive functioning have led them to discount future payoffs associated with longterm educational goals (e.g., by moderating the formation of educational utility beliefs), exert lesser self-control in their pursuit, and manifest a behavioral repertoire that is prohibited in schools. Finally, because males tend to be farther toward the fast end of the life history spectrum than females, they will 
likely be overrepresented among those experiencing such outcomes. Indeed, recent literature suggests that on average, males have poorer academic achievement and more discipline occurrences in primary school (Cornwell et al. 2013), have greater incidence of high school dropout (Heckman and LaFontaine 2010), and are less likely to graduate college (Goldin et al. 2006).

\section{Principles for an Evolutionarily Informed Secondary Education}

Drawing on the evolutionary perspective described above, we have identified several theoretical principles for working with secondary students' evolved information processing biases. Our list of principles should not be seen as exhaustive but, instead, serves as a starting point for identifying evolutionarily consistent educational approaches. That is, in addition to guiding the development of novel educational and psychological models, we contend that evolutionary theory should be used to identify existing approaches that already appear effective and also happen to be evolutionarily consistent. Below, we use this list to identify one such educational approach. We hope our theoretical principles will stimulate additional work at the interface of evolutionary psychology and education, including studies validating these principles.

\section{Principles of an Evolutionarily Consistent Secondary Education}

1. Core content is related to students' intuitive understandings of folk domains.

2. Core knowledge is framed as information that can be used to achieve resource control, status, and mates.

3. Educational processes that match students' inherent preferences for exploration and play, storytelling, and apprenticeship-like pedagogy are employed.

4. Extensive scaffolding enables students to make all the connections implied above in spite of the challenges they face in terms of development. This is particularly relevant among at-risk students who have inhabited harsh and unpredictable environments.

\section{Context-Based Education: an Evolutionarily Consistent Approach}

Contextualized approaches to education may be better suited to adolescents' developing brains and levels of executive functioning than traditional approaches. By providing students with scaffolding and real-world experience (i.e., active or experiential learning), they may decrease the load on the immature substrate in the frontal cortex and thereby facilitate learning and the formation of positive educational expectancies or utility beliefs. This may occur because contextualized approaches leverage evolved biases or biologically primary learning (e.g., learning through movement, collective working memory, and/or embodied cognition) in the service of more evolutionarily novel or biologically secondary learning (e.g., mathematics), ultimately lessening the cognitive load imposed by the latter (see Paas and Sweller 2012). This may also occur because these approaches provide students with experiences that enhance motivation for educational outcomes by revealing how learning could pay off in terms of resource control, status, and perhaps mates, rather than requiring them to deliberately form educational utility beliefs out of context. In turn, this motivation could recalibrate allocation of available cognitive resources to executive functions, such that educational goals are maximally achieved (Pessoa 2009). If these assertions hold true, contextualized approaches may engender the greatest improvements in academic outcomes among at-risk students who exhibit lower levels of executive function and are pursuing short-term payoffs at the expense of embodied capital and longer-term goals. Below, we review a well-studied contextual approach to education known as career and technical education (CTE) and highlight its consistency with our evolutionary principles.

\section{Career and Technical Education}

Career and technical education (CTE), formerly known as vocational education, has been a part of the US high school experience since the beginning of the twentieth century. At that time, American cities, immigration, and industry were expanding, and vocational education was introduced as a way to prepare working class youth for their future in the growing industrial economy (Krug 1969). By the time of the standards-based education reform movement of the 1980s, vocational education had become stigmatized: It was seen as outdated in an economy that was losing manufacturing, and it was considered incapable of producing college-ready youth in a society that valued baccalaureate degrees. The CTE field integrated academic subjects into its programs, contextualizing for students the math or science concepts that are embedded in programs such as automotive technology or health occupations. In the early twenty-first century, vocational education renamed itself CTE to reflect the shift to preparing students for further education and training for the contemporary workforce, offering programs such as biotechnology, preengineering, and culinary arts. Throughout this time, despite the stigma among educators, CTE has remained popular among adolescents, perhaps because CTE provides opportunities for students to engage in work activities with real consequences, and to develop identities and relationships with adults other than teachers or family members (Hall and Raffo 2004). In addition, CTE programs can help students see a 
purpose for learning academic subjects beyond school achievement (Castellano et al. 2012).

\section{CTE as Evolutionarily Consistent}

Linking Academic Content and students' Biases for Folk Domains. By embedding core content within technical programs, CTE provides real-world stimuli that can activate students' folk information processing and motivational biases for learning about and controlling their worlds. CTE provides students with contexts in which it is possible to integrate sensory information about the world, motivation for learning about and controlling it, and scientific information about how it works. For instance, core math and science concepts are embedded in programs like pre-engineering or automotive technology that activate biases for folk physics, while nursing and biotechnology programs embed core biology and chemistry content into contexts where stimuli can activate biases for folk biology. This integration of context and core content may leverage biologically primary learning in service of biologically secondary learning, lessening the load that core biology or physics content places on working memory (Paas and Sweller 2012). This integration may also allow the shortcomings of our folk biases to become readily apparent, highlighting the value added by core content (i.e., folk biases may be effectively challenged in this way). However, it is also possible that some folk biases interfere with biologically secondary learning (e.g., intuitions about species change seem to function as a barrier to understanding evolution [Shtulman 2006]). The application of cognitive load theory (see Paas and Sweller 2012) to context-based learning could reveal important information about how and when contextualized approaches may be more or less useful. Another key contribution of contextbased approaches likely stems from their activation of students' motivational biases for learning and controlling their worlds, which may help to recruit available cognitive resources to focus or maximize executive functioning. Indeed, it is motivation that puts core content to work, not the reverse.

Framing Core Knowledge as Useful for Achievement of Resource Control, Status, and Mates. While CTE may not intentionally highlight how students' motivations for resource control, status, and mates are consistent with career pathways, CTE students build relationships with adults ${ }^{2}$ that work with their biases for learning through exploration, storytelling, and apprenticeship-like pedagogy. These relationships

\footnotetext{
${ }^{2}$ It is notable that people seem to have a preference for learning from individuals who are older and seem to have more experience. This preference may be implicit, rather than stemming from evidence indicating that experience usually implies greater skill, knowledge, or performance. Indeed, growing evidence actually tends to challenge this notion (Blow et al. 2007; Mosing et al. 2014; Rice 2010).
}

allow them to explore and learn about the career trajectories that characterize various fields. This learning can occur through field-based stories that adults share with students as well as through the work-based learning experiences common to many CTE programs. These experiences can help students see what a career in nursing or engineering might look like in terms of embodied capital, status, income, and/or health, etc. In this way, motivation for learning might be increased, which could then enhance executive functioning as more cognitive resources are devoted to it. Moreover, such experiences may work with students' current levels of executive functioning better than traditional classroom instruction, which likely requires students to engage in more effortful formation of educational utility beliefs.

Matching Educational Processes with Students' Inherent Learning Preferences. CTE works with students' biases for learning through exploration, storytelling, and apprenticeshiplike pedagogy. Below, we review how CTE is consistent with students' evolved biases for these learning processes, drawing on foundational scholarship in context-based learning.

Apprenticeship. As mentioned, CTE works with students' preference for learning through apprenticeship-like pedagogy. Such pedagogy occurs informally (e.g., in the context of village-based learning) and also in apprenticeships that are formally arranged (Lancy 2012). In this section, we use "apprenticeship" in reference to the pedagogy of apprenticeship rather than the institution (see Lancy 2012, p. 120). Later, we discuss formal apprenticeships as well.

Apprenticeship supports the social aspect of learning - apprentices observe the target practice, are guided or scaffolded by the master, and practice until they can approximate the performance. This learning through guided experience happens most naturally in physical learning because the processes to learn are visible and available to observe and reproduce. There is also a transparent relationship between process and product. These characteristics are not naturally the case for learning academic subjects in school. Brown et al. (1989) noted the inherent motivation to develop physical skills: concrete rewards for quality products. This contrasts with the mastering of academic subjects, the rewards for which are not always clear, relevant, or aspired to by adolescents.

Apprenticeship also encompasses the active aspect of learning: apprentices watch and do. In a review of programs designed to teach critical thinking skills, the most effective programs were "organized around joint accomplishment of tasks, so that elements of the skill take on meaning in the context of the whole" (Resnick 1987b, p. 13). This approach can and has been applied to academic subjects (see Collins et al. 1989, for a review), but it is not the norm. It is uncommon for high school teachers to know enough about the 
academic subject matter they teach to act as practitioners. But, in a CTE program, teachers often come from industry, might have apprenticed or interned themselves, and are more likely to be doing physical skill development, especially demonstrating the use of tools.

Exploration Through Project-Based Learning. CTE programs provide opportunities for students to explore real work activities with real consequences, thereby working with students' preference for learning through exploration. CTE often involves project-based learning, or extended inquiry in response to an actual problem, another hallmark of learning outside of school. Learning from projects requires learners to formulate the problem and then deal with the other problems that arise while carrying out the project. Learning becomes a "sense-making pursuit that grapples with ill-defined problems" (Brown et al. 1989, p.10), not an exercise in which the odd-numbered answers are at the back of the text. Examples from CTE include media students writing and broadcasting the school news program, culinary students running the school café, and biotechnology students identifying the types of bacteria in local pond water. There is no single way to accomplish these tasks, nor one correct "answer."

Storytelling. Storytelling is another feature of evolutionarily consistent learning. Lave and Wenger (1991) posited that stories are central to learning because it is through stories that novices learn about the kinds of contexts in which experts make judgements and decisions. That is, stories are "packages of situated knowledge" (Jordan 1989, p. 935). Storytelling is more likely to function as a learning mode in CTE than in other curricular areas of the high school: Guest speakers from relevant industries visit CTE classrooms, shops, and labs to talk about their careers. They recount stories from the workplace that help students understand what those careers are like and the kinds of decisions and situations they might encounter.

Scaffolding Students to Make Connections. By now, it may be apparent that the contexts in context-based approaches like CTE do the work of scaffolding adolescents to connect core content to their understandings of folk domains and the outcomes they are motivated to achieve. This may occur because these contexts allow biologically primary learning to facilitate biologically secondary learning (Paas and Sweller 2012). For instance, during formal apprenticeships, the workplace stories that students' mentors share help students understand what careers are like and the kinds of decisions and situations they might encounter. In these stories, intuitions related to folk domains, core content, and success and challenges in achieving outcomes adolescents care about are linked together, as Jordan (1989) noted, in packages of situated knowledge. Perhaps stories are stored in long-term memory more easily than written information because they draw on some combination of biologically primary learning processes such as audiovisual learning and embodied cognition (Paas and Sweller 2012).

During formal apprenticeships, tools also provide a source of scaffolding because they are physical manifestations of the contextualized knowledge to be acquired. In a biotechnology program, for example, biology is not only found in the textbook; it is instantiated in the tools and equipment that allow students to isolate and study DNA. The tools and the project themselves are the scaffolds, and they likely enhance biologically secondary learning through primary learning means such as human movement effects and embodied cognition (Paas and Sweller 2012).

Finally, project-based learning usually includes collaborative problem solving, providing another source of scaffolding: one's peers. Typically, academic classes require students to work alone. Research suggests that such collaborative problem solving with peers enhances biologically secondary learning through collective working memory effects, or by enabling people to reduce the cognitive load of secondary learning through communication (Paas and Sweller 2012). In this way, project-based learning as implemented in the best CTE programs engage students socially and emotionally, enabling them to better understand the meaning and purpose of what they are learning. Furthermore, CTE programs encourage the use of twenty-first-century skills (i.e., analyzing, evaluating, inquiring, and formulating), put teachers in the background and students in the foreground, offer interaction with and presentation to adults outside of the school, and connect students and schools to communities (Markham et al. 2003).

CTE Versus Conventional Schooling. To further illustrate the evolutionarily consistent nature of CTE, it is helpful to contrast it against conventional schooling. Learning is largely an active, constructive process, rather than a simple transfer of knowledge (Resnick 1987a, b). This construction process does not occur in a vacuum - certain contexts foster the creation of knowledge, and others, such as a traditional classroom, foster a more passive type of learning in which the learner listens to and receives knowledge (Lave 1988). In fact, the school setting may be quite antithetical to students' evolved learning biases.

Resnick (1987a) examined learning both in school and out, noting that schools lack the context for the adequate engagement of tools, other artifacts, and people. According to Paas and Sweller (2012), these are just the sorts of engagements that can leverage biologically primary learning in service of secondary learning (e.g., through movement effects or collective memory effects). In conventional schooling, using objects or people to help one learn can be considered cheating (i.e., a calculator and talking to a peer). Conventional schooling also presents content almost exclusively via teacher-directed instruction, which may discourage development of a variety of 
strategies for enhancing higher order cognition (i.e., thinking about the thinking and problem solving in which one is engaged). Resnick found that effective out-of-school learning settings involved learners in socially shared intellectual work, such as group projects. In addition to the modeling that occurs in such a group setting (in which learners watch other more skilled participants perform), the social context provides a scaffold for the learner, allowing her to participate despite being a novice. Such contexts contain elements of apprenticeship, in which learners of all levels participate and develop their range and competence gradually. In general, this sort of out-of-school learning seems more consistent with the leveraging of biologically primary learning processes as strategies for learning biologically secondary information.

It is difficult for academic core classes to incorporate these aspects of learning which occur in out-of-school learning situations. CTE, in its best incarnations (Kelly and Price 2009), already provides all of these elements. Of course CTE, like any topic, can be taught ineffectively, and some career areas foster broader learning than others. But, in high-quality CTE programs (Holzer et al. 2013), students often work on projects that teach them knowledge and skills that in some way derive from academic subjects (i.e., understanding the results of a biotechnology experiment and writing the morning's school newscast). What students learn is embedded in the activity; the project itself scaffolds the academic learning (Collins et al. 1989), giving students a context in which to place useful academic knowledge.

CTE is not alone in the potential to bring this type of learning to adolescents - the arts and physical education readily provide similar hands-on, student-directed experiences. However, these subjects are not taught in ways that cultivate core academic knowledge. Another advantage of CTE is that it prepares adolescents for future careers, which is of interest to both adolescents and society and addresses the societal mission of schooling (Resnick 1987a). Academic instruction can also be designed to be more evolutionarily consistent and relevant to the concerns of adolescents, usually through project-based learning (Markham et al. 2003). These ideas are not necessarily new-John Dewey reported the value of such an approach nearly a century ago (Dewey 1916). But, despite this, most instruction in high school remains antithetical to adolescent concerns and their learning proclivities, and this appears to affect at-risk students to a greater degree, leading to disengagement and dropout.

\section{Conclusions and Future Directions}

Our analysis of CTE reveals that this context-based approach to education is consistent with at least three (i.e., \#s 1, 3, and 4) of our four (i.e., not \#2) theoretical principles for evolutionarily informed education, and it touches on \#2. CTE works within student biases in attention and motivation and can therefore alleviate some of the environmental mismatch contributing to poor achievement, discipline occurrences, and dropout. Interestingly, educators and the rest of society have not framed CTE as a pathway to resource control, status, and mates. Instead, CTE has been stigmatized and regarded as a safety net for those who cannot thrive in traditional educational environments and are unlikely to succeed in college. This has occurred despite evidence that (1) CTE is neutral to beneficial to most students in terms of college aspiration and attendance (Betts et al. 2014; Castellano et al. 2014; Neild et al. 2013); (2) there is widespread college dropout prior to degree completion, often with student loan debt (Gladieux and Perna 2005), resulting from a college-for-all mission in the nation's high schools (Rosenbaum 2011); and (3) careers in CTE-related fields can deliver stable employment and substantial income (Kemple and Willner 2008; Meer 2007). While our analysis suggests that CTE may add great value to traditional educational approaches by incorporating required learning into learning environments that appeal to adolescents, it also indicates that the CTE community should investigate potential strategies for marketing its programs as status bearing. If CTE can be seen as a legitimate way to pursue resource control, status, and mates, adolescents may be able to go through high school learning in an evolutionarily consistent manner that mitigates discipline occurrences and dropout and allows adolescents to develop better informed plans for adulthood.

Our application of ecological and evolutionary principles to CTE also suggests two additional directions for future evolutionarily informed work. First, it suggests that major aspects of CTE could be seen as parts of an evolutionary toolbox for improving secondary educational outcomes. We suggest that in addition to guiding the development of novel solutions to social problems, evolutionary theory can be used to identify effective approaches that already exist, are consistent with its principles, but may be underappreciated. It is our hope that the theoretical principles we have identified here can serve this purpose for researchers in evolutionary psychology and related fields who are interested in applications to education and educational psychology. Perhaps in the future, such work can lead to the integration of educational approaches into a more coherent framework that provides pathways to careers that are viable for students who are dissimilar in their childhood ecologies, abilities, and aspirations. Toward this end, the application of cognitive load theory (see Paas and Sweller 2012) to CTE could lead to important new insights into when and how context-based learning facilitates biologically secondary learning.

Finally, our analysis suggests that the beneficial outcomes of CTE may be larger among at-risk adolescents, for whom the scaffolding provided by context-based approaches should be most helpful because their experiences and executive functioning have led them to discount the utility of educational 
outcomes as a part of a fast LHS. Despite CTE's historical association with students who experienced academic difficulty, along with some empirical evidence that CTE is helpful to such students (Campbell and Laughlin 1988; Mertens et al. 1982; Plank 2001; Stone and Aliaga 2014), no theoretical account of why this should be the case has hitherto been developed. Thus, we see the theoretical development presented in this article as an important contribution. Our analysis suggests that future research into the effects of CTE on student achievement should disaggregate participants by risk status to test the proposition that approaches like CTE can alleviate some of the greater mismatches that occur between students from harsh environments and the characteristics of standard secondary education.

\section{References}

Alloway, T. P., \& Alloway, R. G. (2010). Investigating the predictive roles of working memory and IQ in academic attainment. Journal of Experimental Child Psychology, 106(1), 20-29. doi:10.1016/j.jecp. 2009.11.003.

Ardila, A. (2008). On the evolutionary origins of executive functions. Brain and Cognition, 68(1), 92-99. doi:10.1016/j.bandc.2008.03. 003.

Aronen, E. T., Vuontella, V., Steenari, M. R., Salmi, J., \& Carlson, S. (2004). Working memory, psychiatric symptoms, and academic performance at school. Neurobiology of Learning and Memory, 83(1), $33-42$.

Barkley, R. A. (2001). The executive functions and self-regulation: an evolutionary neuropsychological perspective. Neuropsychology Review, 11(1), 1-29.

Betts, J. R., Zau, A., McAdams, J., \& Dotter, D. (2014). Career and technical education in San Diego: a statistical analysis of course availability, students' course-taking patterns, and relationships between high school and postsecondary outcomes. San Diego: San Diego Educational Research Alliance.

Blow, A. J., Sprenkle, D. H., \& Davis, S. D. (2007). Is who delivers the treatment more important than the treatment itself? The role of the therapist in common factors. Journal of Marital and Family Therapy, 33(3), 298-317. doi:10.1111/j.1752-0606.2007.00029.x.

Brown, D. E. (1991). Human universals. New York: McGraw-Hill.

Brown, J. S., Collins, A., \& Duguid, P. (1989). Situated cognition and the culture of learning. Educational Researcher, 18(1), 32-42.

Buss, D. M. (2008). Evolutionary psychology: the new science of the mind (3rd ed.). Austin, TX: Pearson Education Inc.

Campbell, A. A. (2002). Mind of her own: the evolutionary psychology of women. Oxford, U.K.: Oxford University Press.

Campbell, P. B., \& Laughlin, S. (1988). Participation in vocational education: An overview of patterns and their outcomes. Columbus, $\mathrm{OH}$ : National Center for Research in Vocational Education.

Carbon, C. C., \& Albrecht, S. (2012). Bartlett's schema theory: the unreplicated "portrait d'homme" series from 1932. The Quarterly Journal of Experimental Psychology, 65, 2258-2270. doi:10.1080/ 17470218.2012.696121.

Castellano, M., Sundell, K. E., Overman, L. T., \& Aliaga, O. A. (2012). Do career and technical education programs of study improve student achievement? Preliminary analyses from a rigorous longitudinal study. International Journal of Educational Reform, 21, 98-118.
Castellano, M., Sundell, K. E., Overman, L. T., Richardson, G. B., \& Stone, J. R., III. (2014). Rigorous tests of student outcomes in CTE programs of study: final report. Louisville, KY: National Research Center for Career and Technical Education, University of Louisville.

Chisholm, J. S. (1999). Death, hope and sex: steps to an evolutionary ecology of mind and morality. New York, NY: Cambridge University Press.

Collins, A., Brown, J. S., \& Newman, S. E. (1989). Cognitive apprenticeship: teaching the crafts of reading, writing, and mathematics. In L. Resnick (Ed.), Knowing, learning, and instruction: essays in honor of Robert Glaser (pp. 453-494). Hillsdale, NJ: Lawrence Erlbaum Associates.

Conley, A. M. (2012). Patterns of motivation beliefs: combining achievement goal and expectancy-value perspectives. Journal of Educational Psychology, 104(1), 32. doi:10.1037/a0026042.

Conrey, F. R., \& Smith, E. R. (2007). Attitude representation: attitudes as patterns in a distributed, connectionist representational system. Social Cognition, 25(5), 718-735. doi:10.1521/soco.2007.25.5.718.

Cornwell, C., Mustard, D. B., \& Van Parys, J. (2013). Noncognitive skills and the gender disparities in test scores and teacher assessments: evidence from primary school. Journal of Human Resources, 48(1), 236-264.

Cross, C. P., Copping, L. T., \& Campbell, A. (2011). Sex differences in impulsivity: a meta-analysis. Psychological Bulletin, 137, 97-130. doi:10.1037/a0021591.

Damasio, A. (2003). Looking for Spinoza, Joy, sorrow, and the feeling brain. New York: Harcourt, Brace \& Company.

Del Giudice, M. (2009). Sex, attachment, and the development of reproductive strategies. Behavioral and Brain Sciences, 32(01), 1-21. doi:10.1017/S0140525X09000016.

Del Giudice, M. (2014). An evolutionary life history framework for psychopathology. Psychological Inquiry, 25, 261-300. doi:10.1080/ 1047840X.2014.884918.

Del Giudice, M., Ellis, B. J., \& Shirtcliff, E. A. (2011). The adaptive calibration model of stress responsivity. Neuroscience \& Biobehavioral Reviews, 35(7), 1562-1592. doi:10.1016/j. neubiorev.2010.11.007.

Dewey, J. (1916). Democracy in education: an introduction to the philosophy of education. New York: Macmillan.

Duckworth, A. L., \& Carlson, S. M. (2013). Self-regulation and school success. Self-regulation and autonomy: social and developmental dimensions of human conduct, 40, 208.

Duckworth, A., \& Gross, J. J. (2014). Self-Control and Grit Related but Separable Determinants of Success. Current Directions in Psychological Science, 23(5), 319-325. doi:10.1177/ 0963721414541462.

Eccles, J. S., \& Wigfield, A. (2002). Motivational beliefs, values, and goals. Annual Review of Psychology, 53(1), 109-132.

Eccles, J. S., Midgley, C., Wigfield, A., Buchanan, C. M., Reuman, D., Flanagan, C., \& Mac Iver, D. (1993). Development during adolescence: the impact of stage-environment fit on young adolescents' experiences in schools and in families. American Psychologist, 48(2), 90-101. doi:10.1037/0003-066X.48.2.90.

Ellis, B. J., Figueredo, A. J., Brumbach, B. H., \& Schlomer, G. L. (2009). Fundamental dimensions of environmental risk: the impact of harsh versus unpredictable environments on the evolution and development of life history strategies. Human Nature, 20, 204-268. doi:10. 1007/s12110-009-9063-7.

Ellis, B. J., Del Giudice, M., Dishion, T. J., Figueredo, A. J., Gray, P., Griskevicius, V., \& Wilson, D. S. (2012). The evolutionary basis of risky adolescent behavior: implications for science, policy, and practice. Developmental Psychology, 48(3), 598-623. doi:10.1037/ a0026220.

Figueredo, A. J., \& Jacobs, W. J. (2010). Aggression, risk-taking, and alternative life history strategies: the behavioral ecology of social deviance. In M. Frias-Armenta \& V. Corral-Verdugo 
(Eds.), Bio-psychosocial perspectives on interpersonal violence (pp. 3-28). Hauppauge, NY: NOVA Science Publishers.

Figueredo, A. J., Va'squez, G., Brumbach, B. H., Schneider, S., Sefcek, J. A., Tal, I. R., \& Jacobs, W. J. (2006). Consilience and life history theory: from genes to brain to reproductive strategy. Developmental Review, 26, 243-275. doi:10.1016/j.dr.2006.02.002.

Gallistel, C. R., \& Gelman, R. (1992). Preverbal and verbal counting and computation. Cognition, 44(1), 43-74. doi:10.1016/0010-0277(92) 90050-R.

Gangestad, S. W., \& Simpson, J. A. (2000). The evolution of human mating: trade-offs and strategic pluralism. Behavioral and Brain Sciences, 23, 573-587. doi:10.1017/S0140525X0000337X.

Gatzke-Kopp, L. M. (2011). The canary in the coalmine: the sensitivity of mesolimbic dopamine to environmental adversity during development. Neuroscience \& Biobehavioral Reviews, 35(3), 794-803. doi: 10.1016/j.neubiorev.2010.09.013.

Geary, D. C. (2011). Application of evolutionary psychology to academic learning. Applied Evolutionary Psychology, 78-92. doi: 10.1093/ acprof:oso/9780199586073.001.0001.

Geary, D. C., \& Flinn, M. V. (2001). Evolution of human parental behavior and the human family. Parenting: Science and Practice, 1, 5-61.

Geary, D. C., Byrd-Craven, J., Hoard, M. K., Vigil, J., \& Numtee, C. (2003). Evolution and development of boys' social behavior. Developmental Review, 23(4), 444-470.

Giedd, J. N., Blumenthal, J., Jeffries, N. O., Castellanos, F. X., Liu, H., Zijdenbos, A., Paus, T., Evans, A. C., \& Rapoport, J. L. (1999). Brain development during childhood and adolescence: a longitudinal MRI study. Nature Neuroscience, 2(10), 861-863. doi:10.1038/ 13158.

Gilbert, P. (1998). The evolved basis and adaptive functions of cognitive distortions. British Journal of Medical Psychology, 71, 447-463.

Gladieux, L., \& Perna, L. (2005). Borrowers who drop out: a neglected aspect of the college student loan trend (Report \#05-2). San Jose, CA: National Center for Public Policy and Higher Education.

Goldin, C., Katz, L. F., \& Kuziemko, I. (2006). The homecoming of American college women: the reversal of the college gender gap. Journal of Economic Perspectives, 20, 133-156.

Goldman, M. S., Darkes, J., Reich, R. R., \& Brandon, K. O. (2006). From DNA to conscious thought: the influence of anticipatory processes on human alcohol consumption. In M. Munafo \& P. Albery (Eds.), Cognition + Addiction (pp. 146-184). Great Clarendon Street, Oxford: Oxford University Press.

Hall, D., \& Raffo, C. (2004). Re-engaging 14-16-year-olds with their schooling through work-related learning. Journal of Vocational Education and Training, 56, 69-80. doi:10.1080/ 13636820400200246.

Hallfors, D., Vevea, J. L., Iritani, B., Cho, H., Khatapoush, S., \& Saxe, L. (2002). Truancy, grade point average, and sexual activity: a metaanalysis of risk indicators for youth substance use. Health and Well Resource Center, 72(5), 205-212.

Hansen, W. B., Dusenbury, L., Bishop, D., \& Derzon, J. H. (2007). Substance abuse prevention program content: systematizing the classification of what programs target for change. Health Education Research, 22(3), 351-360. doi:10.1093/her/cyl091.

Harackiewicz, J. M., Rozek, C. S., Hulleman, C. S., \& Hyde, J. S. (2012). Helping parents to motivate adolescents in mathematics and science an experimental test of a utility-value intervention. Psychological Science. doi:10.1177/0956797611435530.

Haselton, M. G., Nettle, D., \& Andrews, P. W. (2005). The evolution of cognitive bias. In D. M. Buss (Ed.), The handbook of evolutionary psychology (pp. 724-746). New York, NY: Wiley.

Haselton, M. G., Bryant, G. A., Wilke, A., Frederick, D. A., Galperin, A., Frankenhuis, W. E., \& Moore, T. (2009). Adaptive rationality: an evolutionary perspective on cognitive bias. Social Cognition, 27(5), 733-763. doi:10.1521/soco.2009.27.5.733.
Heckman, J. J., \& LaFontaine, P. A. (2010). The American high school graduation rate: trends and levels. The Review of Economics and Statistics, 92(2), 244-262.

Higgins, E. T., \& Spiegal, S. (2004). Promotion and prevention strategies for selfregulation: a motivated cognition perspective. In R. F. Baumeister \& K. D. Vohs (Eds.), The Handbook of SelfRegulation (pp. 171-187). New York, NY: The Guilford Press.

Hindson, B., Byrne, B., Fielding-Barnsley, R., Newman, C., Hine, D. W., $\&$ Shankweiler, D. (2005). Assessment and early instruction of preschool children at risk for reading disability. Journal of Educational Psychology, 97(4), 687-704. doi:10.1037/0022-0663.97.4.687.

Holzer, H. J., Linn, D., \& Monthey, W. (2013). The promise of highquality career and technical education: improving outcomes for students, firms, and the economy. Washington DC: The College Board and the Georgetown Law Center on Poverty, Inequality, and Public Policy.

Jordan, B. (1989). Cosmopolitical obstetrics: some insights from the training of traditional midwives. Social Science and Medicine, 28 , 925-944.

Kaplan, H. S., \& Gangestad, S. W. (2005). Life history theory and evolutionary psychology. In D. M. Buss (Ed.), The handbook of evolutionary psychology (pp. 68-95). New York, NY: Wiley.

Kelly, S., \& Price, H. (2009). Vocational education: a clean slate for disengaged students? Social Science Research, 38, 810-825.

Kemple, J. J., \& Willner, J. (2008). Career academies: long-term impacts on labor market outcomes, educational attainment, and transitions to adulthood. New York: MDRC.

Krug, E. A. (1969). The shaping of the American high school. Madison, WI: University of Wisconsin Press.

Kruger, D. J., Reischl, T., \& Zimmerman, M. A. (2008). Time perspective as a mechanism for functional developmental adaptation. Journal of Social, Evolutionary and Cultural Psychology, 2, 1-22. doi:10. 1037/h0099336.

Laidra, K., Pullmann, H., \& Allik, J. (2007). Personality and intelligence as predictors of academic achievement: a cross-sectional study from elementary to secondary school. Personality and Individual Differences, 42(3), 441-451. doi:10.1016/j.paid.2006.08.001.

Lancy, D. F. (2010). Learning 'from nobody': the limited role of teaching in folk models of children's development. Childhood in the Past, 3(1), 79-106.

Lancy, D. F. (2012). "First you must master pain": the nature and purpose of apprenticeship. Anthropology of Work Review, 33(2), 113-126. doi:10.1111/j.1548-1417.2012.01084.x.

Lave, J. (1988). Cognition in practice: mind, mathematics, and culture in everyday life. Cambridge, UK: Cambridge University Press.

Lave, J., \& Wenger, E. (1991). Situated learning: legitimate peripheral participation. Cambridge, UK: Cambridge University Press.

Lende, D. H., \& Smith, E. O. (2002). Evolution meets biopsychosociality: an analysis of addictive behavior. Addiction, 97(4), 447-458. doi:10.1046/j.1360-0443.2002.00022.x.

Markham, T., Larmer, J., \& Ravitz, J. (2003). Project-based learning handbook: a guide to standards focused project based learning for middle and high school teachers. Novato, CA: Buck Institute for Education.

Mealey, L. (1999). Evolutionary models of female intrasexual competition. Behavioral and Brain Sciences, 22(2), 234-234.

Mertens, D. M., Seitz, P., \& Cox, S. (1982). Vocational education and the high school dropout. Columbus, OH: National Center for Research in Vocational Education.

Meer, J. (2007). Evidence on the returns to secondary vocational education. Economics of Education Research, 26, 559-573.

Mischel, W. (2014). The Marshmallow Test: Mastering selfcontrol. New York, NY: Little, Brown.

Mosing, M. A., Madison, G., Pedersen, N. L., Kuja-Halkola, R., \& Ullén, F. (2014). Practice Does Not Make Perfect No Causal Effect of 
Music Practice on Music Ability. Psychological Science, 25, 1795 1803.

Nation, M., Crusto, C., Wandersman, A., Kumpfer, K. L., Seybolt, D., Morrissey-Kane, E., \& Davino, K. (2003). What works in prevention: principles of effective prevention programs. American Psychologist, 58(6-7), 449-456. doi:10. 1037/0003-066X.58.6-7.449.

Neild, R., Boccanfuso, C., \& Byrnes, V. (2013). The academic impacts of career and technical schools: a case study of a large urban district. Baltimore, MD: Johns Hopkins University, Center for Social Organization of Schools.

Nettle, D. (2009). An evolutionary model of low mood states. Journal of Theoretical Biology, 257, 100-103. doi:10.1016/j.jtbi.2008.10.033.

Paas, F., \& Sweller, J. (2012). An evolutionary upgrade of cognitive load theory: using the human motor system and collaboration to support the learning of complex cognitive tasks. Educational Psychology Review, 24(1), 27-45. doi:10.1007/s10648-011-9179-2.

Pessoa, L. (2009). How do emotion and motivation direct executive control? Trends in Cognitive Sciences, 13(4), 160-166. doi:10.1016/j. tics.2009.01.006.

Plank, S. (2001). Career and technical education in the balance: An analysis of high school persistence, academic achievement, and postsecondary destinations. St. Paul, MN: National Research Center for Career and Technical Education.

Redish, A., Jensen, S., \& Johnson, A. (2008). Addiction as vulnerabilities in the decision process. Behavioral and Brain Sciences, 31, 461470.

Rakic, P., Bourgeois, J. P., \& Goldman-Rakic, P. S. (1994). Synaptic development of the cerebral cortex: implications for learning, memory, and mental illness. Progress in Brain Research, 102, 227-243. doi:10.1016/S0079-6123(08)60543-9.

Resnick, L. B. (1987a). Learning in school and out. Educational Researcher, 16(9), 13-20.

Resnick, L. B. (1987b). Education and learning to think. Washington DC: National Research Council, National Academy Press.

Rhen, T., \& Crews, D. (2002). Variation in reproductive behaviour within a sex: neural systems and endocrine activation. Journal of Neuroendocrinology, 14(7), 517-531.

Rice, T. (2010). Learning to listen: auscultation and the transmission of auditory knowledge. Journal of the Royal Anthropological Institute, 16, S41-S61. doi:10.1111/j.1467-9655.2010.01609.x.

Richardson, G. B., \& Hardesty, P. (2012). Immediate survival focus: synthesizing life history theory and dual process models to explain substance use. Evolutionary Psychology, 10, 731-749.

Richardson, G. B., Chen, C. C., Dai, C. L., Hardesty, P. H., \& Swoboda, C. M. (2014). Life history strategy and young adult substance use. Evolutionary Psychology, 12, 932-957.

Roe, S., \& Becker, J. (2005). Drug prevention with vulnerable young people: a review. Drugs: Education, Prevention, and Policy, 12(2), 85-99. doi:10.1080/0968763042000322639.

Rosenbaum, J. E. (2011). The complexities of college for all: beyond fairy-tale dreams. Sociology of Education, 84, 113-117.

Ross, L. T., \& Hill, E. M. (2002). Childhood unpredictability, schemas for unpredictability, and risk taking. Social Behavior and Personality, 30(5), 453-473.

Schmitt, D. P., Shackelford, T. K., \& Buss, D. M. (2001). Are men really more "oriented" toward short-term mating than women? A critical review of theory and research. Psychology, Evolution and Gender, 3, 211-239. doi:10.1080/14616660110119331.
Shtulman, A. (2006). Qualitative differences between naïve and scientific theories of evolution. Cognitive Psychology, 52(2), 170-194. doi: 10.1016/j.cogpsych.2005.10.001.

Sobeck, J. L., Abbey, A., \& Agius, E. (2006). Lessons learned from implementing school-based substance abuse prevention curriculums. Children and Schools, 28(2), 77-85. doi:10.1093/cs/28.2.77.

Spear, L. P. (2002). Alcohol's effects on adolescents. Alcohol Research and Health, 26(4), 287-291.

Stacy, A. W., \& Wiers, R. W. (2006). An implicit cognition, associative memory framework for addiction. In M. Munafo \& P. Albery (Eds.), Cognition + Addiction (pp. 31-72). Great Clarendon Street, Oxford: Oxford University Press.

Stone, J.R., \& Aliaga, O. (2014). Engaging Students in High School: A Survival Analysis of the Impact of Career and Technical Education. Philadelphia: Annual Meeting of the American Education Research Association.

Taylor, S. F., Welsh, R. C., Wager, T. D., Phan, K. L., Fitzgerald, K. D., \& Gehring, W. J. (2004). A functional neuroimaging study of motivation and executive function. NeuroImage, 21(3), 1045-1054. doi:10. 1016/j.neuroimage.2003.10.032.

Trivers, R. L. (1972). Parental investment and sexual selection. In B. Campbell (Ed.), Sexual Selection and the descent of man (pp. 136-179). Chicago: Aldine-Atherton.

University of Minnesota. (2007). 2007 College student health survey report: Alcohol and Other drug Use - University of MinnesotaTwin Cities. Minneapolis, MN. Available at: http://www.bhs.umn. edu/surveys/survey-results/2007CSHSReport_UMTC/2007CSHS Alcohol-OtherDrug-Use_Report.pdf.

Urbanoski, K. A., \& Kelly, J. F. (2012). Understanding genetic risk for substance use and addiction: a guide for non-geneticists. Clinical Psychology Review, 32(1), 60-70.

van Honk, J., \& Schutter, D. J. (2007). Testosterone reduces conscious detection of signals serving social correction implications for antisocial behavior. Psychological Science, 18(8), 663-667. doi:10. 1111/j.1467-9280.2007.01955.x.

Van Vugt, M., De Cremer, D., \& Janssen, D. P. (2007). Gender differences in cooperation and competition: The male-warrior hypothesis. Psychological Science, 18(1), 19-23. Retrieved from: http:// dx.doi.org/10.1111/j.1467-9280.2007.01842.x.

Wandersman, A., \& Florin, P. (2003). Community interventions and effective prevention. American Psychologist, 58(6-7), 441-448. doi: 10.1037/0003-066X.58.6-7.441.

Weisfeld, G. E. (1999). Evolutionary principles of human adolescence. New York, NY: Basic Books.

Weisfeld, G. E., \& Coleman, D. K. (2005). Further observations on adolescence. In R. L. Burgess \& K. MacDonald (Eds.), Evolutionary perspectives on human development (2nd ed., pp. 331-357). Thousand Oaks, CA: Sage.

Weiss, A., Egan, V., \& Figueredo, A. J. (2004). Sensational interests as a form of intrasexual competition. Personality and Individual Differences, 36(3), 563-573.

Wilson, M., \& Daly, M. (2004). Do pretty women inspire men to discount the future? Proceedings of the Royal Society B: Biological Sciences, 271(4), S177-S179. doi:10.1098/rsbl.2003.0134.

Wood, W., \& Eagly, A. H. (2002). A cross-cultural analysis of the behavior of women and men: implications for the origins of sex differences. Psychological Bulletin, 128, 699-727. doi: 10.1037/0033-2909.128.5.699. 